\title{
Computational Semantics of Time/Negation Interaction
}

\author{
Pascal Amsili \\ IIRI'l', Universitio l'aul Sabation \\ 118, ronto de Narbonne \\ fi-31062 Toulouse Cedex, Wance \\ amsili@irit.f $r$
}

\author{
Nabil Hathout \\ INaLH CNLS \\ Chattoau du Montet, rue du Doyen Roubault \\ F-54500 Vandouve-lis-Nancy, France \\ hathout@ciril.fr
}

\begin{abstract}
The purpose of this paper is to study the interaction of time and negation in nat,ural langlage, from a syntax/somantics interface point of view. This repuires the delinition of linguistically gromeded semantic and syntactic represontations. This is what we present in this paper; we show how the two representations wo propose fit together in a computationally satisfying construction procedure.
\end{abstract}

\section{Introduction}

We are concerned in this paper with the interaction betweon timo and negation in formal semantics, more precisely in the Discourse Representiation Theory framowork (Kanp and Reylo, 1993). Wo are interested here in the compositional construction of semantic representations.

Wo want to show, through linguistic arguments, that the best semantic representation (at loast for: sentiontial negation) gives negation a wide scope over events or states, and that the syntactic results correspond with the semantic ones.

\section{Semantic representation}

J)I' handles events as objects in the language. 'Thus, cach simple sentence introduces into the? representation (at least) one discourse referent, cither an event or a state, corresponding to the eventuality denoted by the VP'.

With this in mind, nogation can oithor bo seen as an operator always having a wide scope over events/states, or as a kind of aspectual operator. According to the first view, negation wonld semantically convey only negative information ("such an eventuality $x$ didn't occur"). According to the second view, negative sentences convey some kind of positive information, at the semantic level: they donote? a certain kind of eventuality.

We want to address this problem here, with a focus on sentential negation in French.

\subsection{The problem}

As we have already said, the two approaches to sentential negation differ with jespect to the scope they assign to the negation operator. To help illustrate this, we shall use the following exiunple, where we assume that (1b) is the (sentential) negation of (1a). A "stiandard" representation of (Ja) is $K_{1, ~}$

(1) a. Joan s'arretia. (Jean stopped.) b. Jean ne s'arreta pas. (Jean didn't stop.)

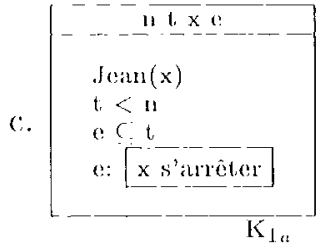

What, $\mathrm{K}_{1 \text { a }}$ says is that there is an $\mathrm{x}$, which is Jean, an event e, and a location time t, such that o is the event of Jean stopping, o is included in tho location timo t, which is itself located in the past of the specelh time n (now). (1b) conk then be represented aither by $\mathrm{K}_{1 b}$ or by $\mathrm{K}_{1 b}^{\prime}$.

(2)

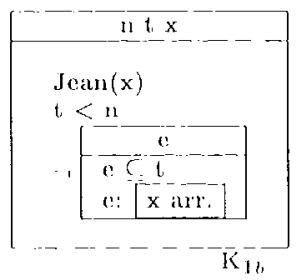

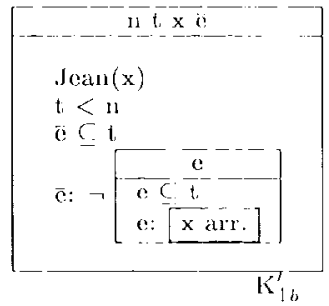

$\mathrm{K}_{16}$ states something like "there is no event of Joan's stopping at the time t." $\mathrm{K}_{16}^{\prime}$ introduces a "speciall" cvent, $\mathrm{i}$, which is clefined in term of the negation of an another event.'

\subsection{Discussion}

'The position we are going to defend here is the one according to which negation should not be seen as

'The ontological and semantic properties of such special events remain to be defined, and the various proponents of this view propose different definitions a sort of "maximal event" (Krifka, 1989), or a state consisting of the negation of an event (de Swart and Molendijk, 1994), for instance. 
an aspectual operator, but rather as having wide scope over the eventuality, as exemplified by the DRS $\mathrm{K}_{1 b}$. This position is the one defended in (Kamp and Reyle, 1993).

We first review the arguments in favour of our view, and then summarize the discussion presented in (Amsili and Le Draoulec, 1996) against the counter-arguments to this view presented in (de Swart and Molendijk, 1994). We summarize our semantic proposal in the section 2.3 .

Simplicity. One of the reasons why we may prefer the representation $K_{1 b}$ to $K_{1 b}^{\prime}$ is that it is simpler, from the technical point of view. Thus, if such a representation is sufficient to account for all the data we want to account for, then there is no need for a more complex representation like the one exemplified in $\mathrm{K}_{1 b}^{\prime}$. Another point worth noting is that the second proposal is also more complex from the ontological point of view. Adding new types of discourse referents like $\bar{e}$ in the language of DRS requires that we define their ontological properties. And since these new kinds are defined in terms of others kinds of discourse referents, this may well be a non-trivial task.

Negation in discourse. The ideas developed in this paragraph are based on a study of negation in discourse currently in progress. The aim of this study is to see how negation interferes with so-called discourse relations (continuation, elaboration, explanation...). To do this, we are using a large corpus taken from French contemporary literature. We shall not describe this study in detail here; nevertheless, one of its findings is relevant to our discussion.

We have looked at examples involving French passé simple (PS, simple past). This tense typically introduces an event rather than a state. We have a set of 1399 examples of sentential negation, in which one find only 46 occurrences of PS. Among these examples, a majority are of the form exemplified in (3).

(3) a. Je ne lui répondis pas. I didn't answer him.

b. Elle ne sursauta pas. She didn't startle.

Thus, in a majority of cases, PS+negation seems to be used to assert the absence of an event, and it is very difficult in those cases to find a "real event" which could be seen as denoted by the sentence.

3 cases in the corpus seem however to suggest that negated event sentences may denote events:

(4) a. Elle ne le voulut pas. She didn't want it.

b. L'autre ne prit pas de détour. The other didn't mince words.

c. Elle ne se laissa pas faire. She didn't let things flow.
Thus, one can easily imagine that (4a) "refers to" a gesture, or some kind of behaviour that could be interpreted as a rofusal. Here, of course, this refusal could probably bo associated with $\overline{\mathrm{e}}$.

But these examples are rare; moreover, the two last sentences of (4) involve more or less idiomatic expressions, so that it seems quite reasonable to see negation here as part of a conventionalised expression ("ne pas se laisser faire" denoting an event, just like the verb to refuse does).

Events can be defined as a change of state. With this definition in mind, we think that, at least in the case of PS, negation over cvents is used mostly to convey something like "nothing changed", or "the expected event didn't occur", and there is in this case no event denoted by the sentence. There remain some cases (very fow) where such sentences seem to denote some real change of the background, but then we claim that negation is lexically incorporated, and no longer sentential.

The classical example. We come now to the "classical" cxample of (Kamp and Reyle, 1993). It involves the following discourses:

(5) a. Mary looked at Bill. He smiled.

b. Mary looked at Bill. He was smiling.

c. Mary looked at Bill. He didn't smile.

d. Mary looked at Bill. He wasn't smiling.

The pair (5a-5b) exemplify the contrast between simple past and progressive past in narrative discourse. In the second sentence of $(5 \mathrm{a})$, the simple past introduces a new event, which is localised after the event introduced in the previous sentence. In constrast, the second sentence of (5b) introduces a state, which overlaps with the event of the previous sentence. This analysis gives the correct prediction for the contrast: in (5a), Bill's smiling is interpreted as a reaction to Mary's looking at Bill, thus following it, whereas in (5b), Bill was already smiling when Mary looked at him.

The contrast in (5c-5d) is clearly parallel to that in $(5 \mathrm{a}-5 \mathrm{~b})$. Since the sccond sentence of $(5 \mathrm{~d})$ can reasonably be thought of as introducing a statc, also introducing a state for the second (negative) sentence of $(5 \mathrm{c})$ would lead us to lose the contrast, since this would suggest for both sentences that Bill was not smiling when Mary looked at him.

Counter-arguments. We summarize here the discussion given in (Amsili and Le Draoulec, 1996) against some of the arguments given in favour of the idea that negative sentences denote an eventuality. There are two main arguments. One is based on the fact that negated event sentences accept durative complements (whereas thcir positive counterpart do not), this fact being taken as an argument in favour of the aspectual role of negation. Our answers are: first, some French data suggest that durative complements with negation should 
not always be seen as demonstrating the durativity of the predicate; second, Kamp and Reyle's (1993) representation provides a satisfying way to account for such data. The second argument is based on examples in which an anaphoric reference seems to be made to the denotation of negative sentences, therefore suggesting that they have onc. But these data are rather constrained, in such a way that it scems that the discourse referent at stake is an abstract one, namely a fact, and not an cvent/state.

\subsection{Proposal}

We can now state the proposal, in the terms of (Kamp and Reyle, 1993, p. 548). Roughly, the interpretation of a negated sentence induces the following steps in the construction of a DRS:

- introduction of a location time t;

- introduction of a condition relating $t$ with the specch time n;

- introduction of a condition saying that there is no event or state of a certain type which stands in the relation ' $\subseteq$ ' $O$ or $^{\prime} O$ ' to t.

As an example, the discourse (5c) will receive the representation (6), the most relevant points of which being, first, that a temporal constant ( $t$ ) is systematically introduced into the representiation, and second, that negation has wide scope over event/state discourse referents, t remaining outside negation.

(6)

\begin{tabular}{|c|c|}
\hline \multicolumn{2}{|r|}{$x$ y $u$ te $u t$} \\
\hline \multirow{4}{*}{\multicolumn{2}{|c|}{$\begin{array}{l}\operatorname{Mary}(x) \\
\operatorname{lill}(y) \\
t<\mathrm{n} \\
\mathbf{c} \leq \mathrm{t}\end{array}$}} \\
\hline & \\
\hline & \\
\hline & \\
\hline e: & $x$ look ant $y$ \\
\hline & $\begin{array}{l}=y \\
<\mathrm{n}\end{array}$ \\
\hline & $e^{\prime}$ \\
\hline$\neg$ & $c \subseteq t^{\prime}$ \\
\hline & $e^{\prime}:$ u smile \\
\hline
\end{tabular}

\section{Syntactic Aspects}

We now briefly address the syntactic aspects of French sentential negation. We adopt the representations envisioned by classical Government and Binding Theory (hereafter G13, Chomsky $(1981 ; 1986))$. Several studies on the structure of Irench clauses, and in particular, negative sentences, have been carried out recently in this framework by Pollock $(1989 ;$ 1993), Hirshbühler and Labolle $(1993 ; 1994 a)$ and Pearce (1994) among others. In this section, we adopt some of their most relevant results.

We are mainly conccrned with two of the four levels of representation of $\mathrm{GB}$, namely $\mathrm{D}$ Structure and S-Structure. The representations of these two levels are trees. D-structures represent basic lexical propertics such as thematic relations. S-structures represent more superficial properties such as case, binding, etc. S-structures derive from D-structures via Move- $\alpha$ : they are the result of movements that take place in the latter. In this section, we attempt to answer the following two questions: (1) what is the D-structure of Fronch negative clauses? (2) which movements take place between D-Structure and S-Structure?

\subsection{Split Inflexion Hypothesis}

The French clause representations we use are rather classical. 'They satisfy $\mathrm{X}^{\prime}$-theory, which uses well-known syntactic concepts independent of any theoretical framework. To represent clanses and to build their DRSs, we use a tree structure consisting of a verb phrase VP dominated by the projection IP of a functional head I bearing the verbal tense and agreoment features (I stands for inflexion). IP has the sentence subject NP' as its specifier and the VI' as the complement of its hearl. The sentence is therefore represented as an "inflexional phrase." 'This may be illustrated by the S-structure (7b) of sentence (7a); (7b) may also be represented as the labelled brackding given in $(7 \mathrm{c}) .^{2}$

(7) a. Julie regarde Mare (Julies looks at Marc.)

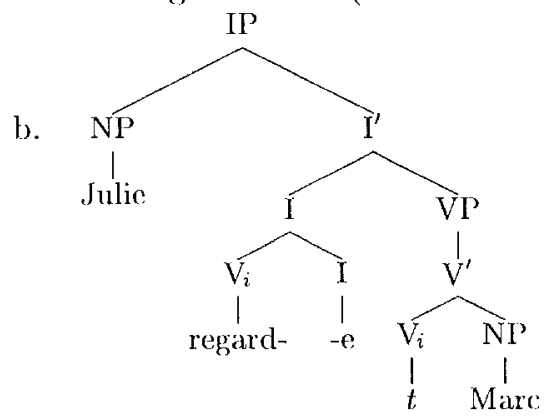

c. [IP [NP Julie $]\left[I^{\prime}\left[I\left[V_{i}\right.\right.\right.$ regard- $]\left[\begin{array}{ll}I & -0\end{array}\right][\mathrm{VP}] \mathrm{V}^{\prime}$ $\left[v_{i}\right.$ t] $\left.\left.\left.\left.[\mathrm{NI}, \mathrm{Marc}]\right]\right]\right]\right]$

Pollock (1989), starting from this general structure, gives a now insight into the problem, by showing the benefits of splitting the complex inflexional category I into two distinct functional categories, namely tense ( $\mathrm{T}$ ) and vorb agreement (Agr). The general structure of French clauses that Pollock (1989) proposes is (8a), so that for instance $(7 \mathrm{~b})$ becomes $(8 \mathrm{~b})$ :

(8) a. ['I'P NI' 'T [ $\left[\operatorname{agr}^{\prime} \ldots \Lambda \mathrm{gr}\left[\mathrm{Ve}^{\prime}(\operatorname{AdvP}) \mathrm{VP}\right]\right]$

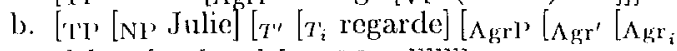
t] $\left.\left.\left.\left[V_{\Gamma},\left[v,\left[v_{i} t\right][N, M a r c \mid]\right]\right]\right]\right]\right]$

\subsection{Negation}

(Pollock, 1989) also claims that negation, like tense and verb agreement, is represented as a functional category, Neg, located between $\mathrm{T}$ and $\Lambda \mathrm{gr}$.

${ }^{2}$ Note that the morphological decomposition of the verb, shown in (7b), will not be made explicit in the following representations. 
In French, this category contains the negative item $n e$, seen as a weak affix lacking morphological stress. In S-Structure, ne must adjoin to the verb as a clitic. More generally, it must raise to $\mathrm{T}$ in finite clauses as well as infinitives.

This proposal has been accepted by many linguists. However, there is no similar consensus about the position in D-Structure and the possible movements of the second element of Fronch negation, namely one of the adverbs pas, plus, point, guère, etc. Here we adopt the proposal of (Hirschbühler and Labelle, 1993) which states that pas (or any of the other negative adverbs) is an adjunct to the maximal projection governed by Neg. Since Neg is located between $\mathrm{T}$ and Agr, this projection is AgrP. The general structure of a French negative clause is therefore:

[TP NP T [NegP Neg [AgrP Agr [VP (AdvP) VP]]]]

\subsection{The Aspectual Dimension of Agr}

The previous clause structure improves significantly the correspondence between syntactic representation and scmantic interpretation. In particular, it becomes easier to differentiate the semantic contribution of each element that is relevant at the aspectuo-temporal level. Thesc elcments fall into two catcgories: those below negation (and therefore inside its scope) and those above negation.

Following (de Freitas, 1994; Borer, 1993; Laka, 1990), we consider Agr to be rather an aspectual category Asp in charge of the aspectual dimension of the semantic representations. This dimension is introduced by discourse referents. Recall that DRT discourse referents do not serve only to account for this aspectual dimension, but do play a fundamental discursive role. Nevertheless, the categorisation into states (s) and events (c) of the utterances to be reprosented, and the possible introduction of the discourse referents of one of these aspectual category, may be associated with the Asp head. This association gives us the expected result: the discourse referent $\mathrm{e}$ or $\mathrm{s}$ is in the scope (in the sense of DRS construction) of the possible negation.

These elements are all illustrated in the complete syntactic representation of the sentence (9) given in figure 2 . Notico the attachment of the sentential adverb aujourd'hui as adjunct to TP, the highest projection of the representation. Bccause of space limitation, we cannot develop this point here and refer the reader to (Amsili, 1994).

(9) Aujourd'hui Pierre ne possède pas de voiture. Today Pierre doesn't own a car.

\section{Bottom-up construction}

We now integrate the semantics and the syntax of sentential negation. We show in this last section that both representations fit together in the framework of a bottom-up construction procedure, which allows a satisfactory computational treatment of negation. We use the method proposed in (Asher, 1993), presented in section 4.1, and then show how this method can be applied to the representations discussed earlicr.

\subsection{Principle}

The construction procedure is bottom-up. DRtheoretic exprossions are associated with leaves, and then combined to form the final DRS. The combinatorial method used here is $\lambda$-conversion, with two kinds of $\lambda$-expressions, namely predicative DRSs and partial DRSs. We associate verbs and nouns with predicative DRSs (for instance, the verb voir (see)) yields $\lambda x \lambda y$ voir $(x, y))$, the role of which is to introduce predicates into the representation. In constrast, discourse referents are only present in the form of DR-variables; they will be introduced by the partial DIRS. The translation of noun phrases (NP) or determincrs is quite close to that of the Montagovian tradition. A determiner is associated with a partial DJRS, which is, so to speak, what remains of a DRS when one takes away a predicative DRS. As a consequence, there will be variables over predicative DRSs (PDRS-variables) in partial DRSs. A partial DRS can also contain a declared discourse referent. This discourse referent is meant to serve as an argument of the predicative DRS which will be assigned to one PDRS-variable during the conversion. In (10) we give a graphical representation of a simple and general case of $\lambda$-conversion.

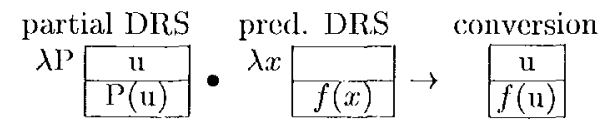

We have no room here to elaborate on the details of the construction procedure; we refer the reader to (Asher, 1993), and give in figure 1 a complete example (with a simplified syntactic representiation), for the sentence (11).

\section{(11) Un gars voyait Maric} A boy was seeing Mary

\subsection{Implementation}

What remains to be done is to integrate this construction procedure with the proposals we have made in this paper. Wo cannot, in this short, text, revicw all aspocts of this integration, and will therefore mention only the most relevant points.

We have seen that the representation of time in DRT makes use of two discourse reforents (at least). It is thus necessary to determine in both cases which node will be in charge of introducing the discourse referent. The pure temporal dimension, which is accounted for by the time referent $t$, will be introduced at the node $T$. The aspectual dimension, which is accounted for at the semantic level by the discourse referent $\mathrm{e} / \mathrm{s}$, is associ- 
Figure 1: Construction of the I)Rs for (11)

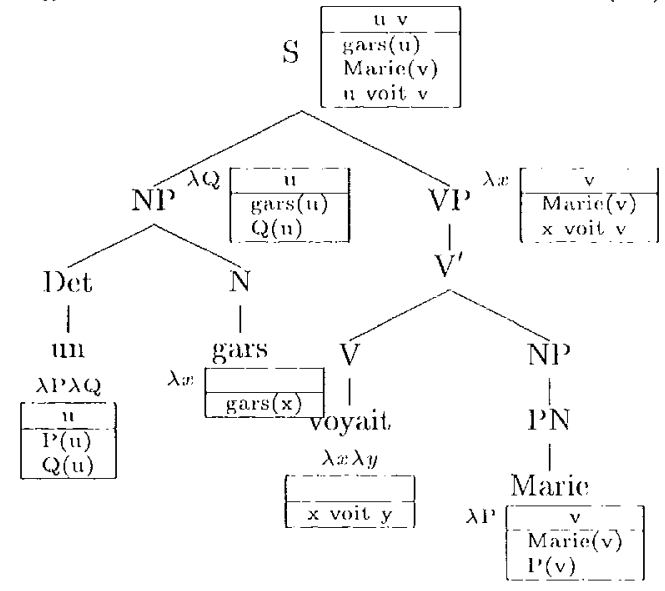

aled with the head $\Lambda$ sp. Wo will therefore associate with this node a partial DRS to introduce the discourse referent. Finally, wo have to take into account the possible role of ternporal adverbials, which predicate over $t$. We associate thus a predicative DRS with the node $\Lambda d v \mathrm{P}^{\prime}$ adjoined to TP. This leads to the complete treatment of time sketched here:

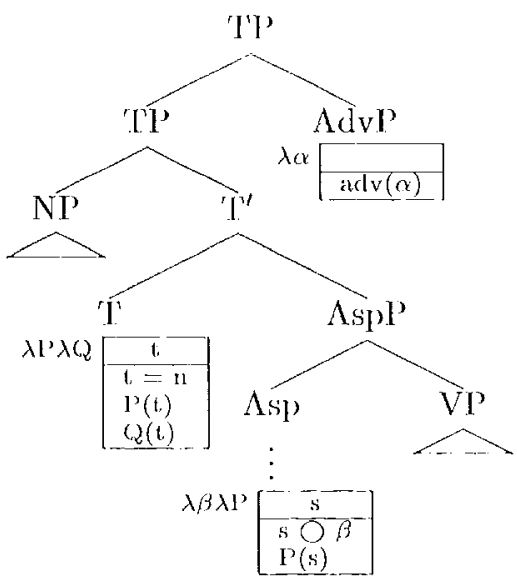

What we have said so far should be sufficient to understand figure 2 (next page), which represents the construction procedure applied to the example (9).

\section{Conclusion}

This work shows the convergence of different approaches, from the syntiax/semantic interfaco point of view. From a semantic point of viow, it, is possible to propose a semantic representation of tomporal negation, and this representation matches in a way recent results in generative syntax, so that it is possible to offer a computationally realistic treatment of this interaction, without any trade-off from the linguistic point of view.

\section{Acknowledgments}

The authors wish to thank Anne Ie Draoulec, Ben Shaer, and latrick Paroubek for their helpfill comments.

\section{References}

P'ascal Amsili and Anno Io Draulec. 1996. An account of negated sentences in the DRT framework. In Ginzburg, Khasidashvili, Isevy, \& Vallduvi eds., The Thilisi Symposium on language, Logic and Computation: selected papers. CSLI Lecture Notes. To appear.

Pascal Amsili. 1994. Calcul de la négution temporelle : le cas da terme présuppositionnel ne... plus. Ph.1) diss., Jniversité 'Toulouse III.

Nicholas Asther. 1993. Reference to Abstract ()bjects in Discourse. Kluwer Acardemic: Jublisher.

Hagit Borcr. 1993. The Projection of Arguments. In Benodicto \& Rumer ods., Innctional Projec-tions. University of Massachusetts, Annherst.

Noam Chomsky. 1981. Lectures on Government and Binding. loris, Dordrecht.

Nodm Chomsky. 1986. Barriers. MIT P'ress, Cambridge, Mass.

Jeslic J. de Froitas. 1994. Syntactic properties of sentential negation; interactions with case, agreement, and (in)definiteness in Wolsh and Russian. Collocue international sur la Négation, Paris $X$, Nanterre.

Hemiëte: do: Swart and Arie Molendijk. 1994. Negation in narrative discourse. In Bunt, Muskems, \& Rontier, ods, Proc. of IWCS'9/, pp. 191 201, Tilburg.

Paul Hirschbühler and Marie Labelle. 1993. Id: status de (no) pas en francais contemporain. Recherche linguistique de Vincenne, 22:31 58.

l'aul Hirschbuibler and Marie Iabelle, 1994a. L'évolution des propositions négatives infinitives en frangais. Colloque international sur la Négation, Paris X, Nanterro.

Hans Kanp and Uwe Reyle. 1993. From discourse to logic. Kluwer Academic Publisher.

Manfred Krifka. 1989. Nominal reference, temporal constitution and quantification in event somantics. In Bartisch, van Benthom \& van Fimde, eds., Semantics and contextual expression, p). 75 115. Foris, Dordrecht.

Miren Itziar Mugarza Laka. 1990. Negation in Syntax: On the Nature of Punctional Categorics and Projection. Ph.D. diss., MIT, Cambridge.

Flisabeth l'earce. 1994. Diachronic change and negation in french. Rivista di Linguistica, 6(1).

Jean-Yves Pollock. 1989. Vorb movement, nuiversal grammar, and the structure of 1.P. Linguistic Inquiry, 20(3):365-424.

Jean-Yves Pollock. 1993. Notes on clause structure, Manuscript, Université de Picardic, Amiens. 
Figure 2: Construction of the DRS for the sentence (9)

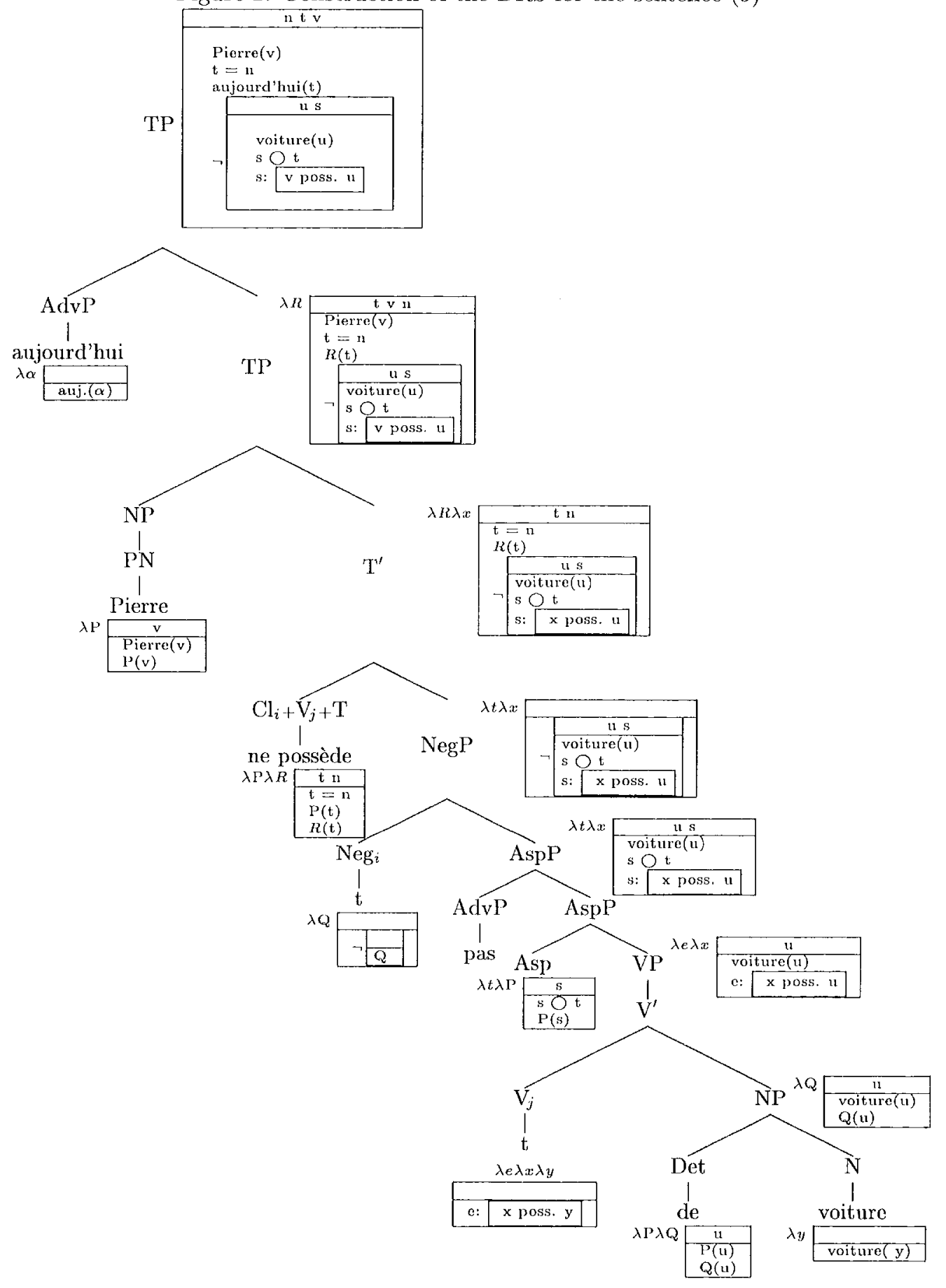

